This is essentially an optimistic book by an author who believes tertiary education will produce a better Fourth Estate. Robie notes New Zealand once led the way in journalism training in the Pacific, a position it has lost to Australia's Ausaid. He reminds readers it was New Zealand that established the South Pacific's first journalism school at UPNG in 1975. He is clear that journalism now is in a better state than before, especially in PNG where a remarkably high percentage of journalists (81 per cent) now have a diploma or degree behind them.

It is a moot point whether those who determine education funding will be swayed by his arguments that universities best provide such education or whether, indeed, the funding debate is worth the candle.

At the risk of overplaying the African parallel, Zimbabwe has recently demonstrated that educated newsrooms cannot necessarily defend democracy. There are few guarantees that can be proffered to funders, but Robie's book is a compelling argument for continuing to try to bolster the Fourth Estate for what lies ahead.
DR DAN BEDGGOOD is a lecturer and researcher at the University of Canterbury. He has published on Pacific cultural encounters and representation.

\section{Hounding the 'great voyager'}

The Trial of the Cannibal Dog: Captain Cook in the South Seas, by Anne Salmond. Auckland: Penguin, 2004, 506 pp. ISBN 0141021330.

To tatou tipuna, ko Kapene Kuki [Our ancestor, Captain Cook] (Te Rangihiroa, cited in Salmond, 2004, p. 425).

COOK is a figure who looms large in the cultural history of the $\mathrm{Pa}$ cific, sailing through the region over the best part of a decade in the late eighteenth century, but leaving a wake ever-expanding to the present. Part of this 'wake' is evident in the considerable space occupied in our literary imagination; yet the chosen pose for this cultural 'ancestor' is variously contended depending on the imaginer's own reflection on history. Cook has had a long reputation as an idealised 'great voyager' and Enlightenment figure, meticulous and rea- 


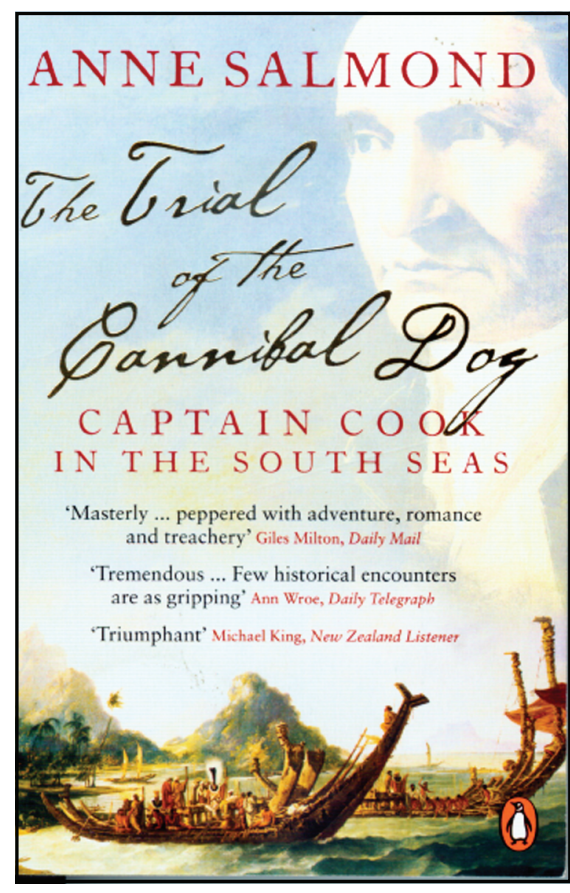

soning in some accounts (see, for example, Beaglehole's editions of Cook's journals), but is also available to be demonised as a representative of and precursor to cultural imperialism and colonialism in the Pacific: the kitchen, it could be said, is already over-populated with 'Cooks'.

Yet for all the many volumes already produced on the subject of Cook, The Trial of the Cannibal Dog, by anthropologist and historian Anne Salmond, should be seen as a valuable addition, in that it extends the scope of the discussion of the voyages and the cultural contact they engendered. Salmond asks new and useful questions of the voyager, those who accompanied him, and those who were 'discovered', and manages to string together her account in a very engaging form. While there remain answers missing from some of those questions, and some, perhaps very important, considerations elided, Salmond's book is largely successful in fusing readability with extensive, rigorous research.

In many ways, Salmond's project mirrors the approach of other recent, local commentators, who apply anthropological methodology to their research, but seek to 'popularise' their own narrative, and who also seek to 'balance' the account by drawing on the other sides of the encounters (see, for example, Calder, Lamb \& Orr, 1999; and Thomas, 2004). For her part, Salmond carefully knits together various 'texts' of the voyagers' accounts while maintaining a tight control over her own 'voice'. Salmond mostly follows a narrative pattern that chronicles the three voyages, keeping the accounts fresh by seeming to journey with the Europeans, yet she also spends time on developing character analyses of the usual suspects (for example, Cook himself, and scientists Banks and the Forsters) and other participants in encounter and mutualobservation. Thus, while Cook's journals and his perspective 
are often central to the narrative, this position is shared with other accounts from his scientist companions, officers and crew, and Salmond takes pains to offer views of what Pacific peoples might have made of their sides of the encounters. For example, Salmond is careful to introduce the local and social contexts of different cultures meeting, spending some time on establishing the dynamism and disruption of 18th century England, represented by the microcosm of Cook's ships as 'floating worlds', and, likewise, analysing factors of change and division in the local societies met by the expeditions which influenced the encounters (such as ariki rivalry in Tahiti or Tongan apprehension towards Cook's hostagetaking).

Some of the obvious strengths of this book are, then, the richnesses of 'thick description' present in the accounts: Salmond displays an acute awareness of the multiple goals and understandings within the chief characters' perspectives, and also an awareness of the hierarchies and divisions on both sides of encounter, and influences and exchanges that took place.

Of particular interest, and pivotal to Salmond's own thesis on the impact and nature of Cook's voyages, are the development of concepts of cultural relativism and class consciousness that both differentiated European and Islander reactions to meetings, and yet also enabled some cross-cultural affiliation.

Cook is represented as being at pains to advance the contradictory goals of plotting the South Seas, advancing understanding of local customs and resources, and establishing 'trade', and yet attempting to minimise the impact of the meetings on local cultures. Salmond seems to stress that this policy, and a strict maintenance of ship discipline, was relatively humane, and Cook was actually disrespected by some of his own men and locals alike because of the apparent 'weakness' implied by this leniency.

The key incident that suggests a response to this attitude of leniency is one that Salmond alludes to in her book's title, an incident which, she contends, influenced a change in tactics that eventually led to Cook's last, lethal confrontation. During Cook's second voyage, his consort ship $A d$ venture lost several men in an encounter with to a raid by local Maori, an incident that was followed up by cannibalism and reciprocal violence by European sailors seeking to find their shipmates.

Cook's leniency here, when he returned to Queen Charlotte's Sound 
on his third voyage, was, as Salmond suggests, both a sign of his attempts towards an enlightened attitude, true to the sentiments of the Royal Society's plea for special treatment of natives, and a mistrust of his own compatriots' tendencies towards punitive measures. Yet Cook's treatment of Kahura, the warrior blamed with the slaughter and subsequent consumption of his men, resulted in both local Maori contempt for a leader not able to seek 'utu', but also a crew who were incensed that 'justice' had not been meted out. As a comment on this, some crew members roasted and consumed a Polynesian dog, a surrogate for the 'cannibals' who had escaped punishment.

Salmond makes this the crucial point in the third voyage, demonstrating the different codes at work in the exchanges between locals and the Europeans, and between different classes of Europeans. Salmond suggests that from this time forth Cook's frustrations at dissent and 'lying' (from both locals and his crew) meant that he began to depart from his more 'enlightened' tactics of encounter (p. 317). Cook became more punitive on board, with the numbers of floggings significantly increased, and, it is suggested, he lost respect for locals, resorting to tactics such as hostage-taking, flogging and the destruc- tive rampage on Mo'orea (pp. 36669), often as punishments for petty theft.

While Salmond does not suggest this as the only cause, she claims that such confrontational tactics were directly responsible for Cook's demise in Hawai'i: 'When he acted with calm restraint, he invited humiliation - his sailors and the islanders alike considered him to be weak and irresolute. When he acted in anger and sought mana by force, he invited retaliation. His men became mutinous, and the islanders sought to kill him' (p. 416).

However, while many of Salmond's observations seem carefully considered, and the narrative style of the whole is generally engaging, some limitations should be noted. The very engaging manner of the style is maintained, at times, at the expense of placing some of the scholarly debate on the page ${ }^{2}$ In particular, the choice of the narrative 'following the action' of the voyages results in many of the repercussions and histories that happened afterwards remaining un- or under-explored. Also, while some of the inquiry of the text has great potential, some of these lines of questioning have not been carried through. For example, there may have been merit in the further development of differing class-consciousness aboard. Finally, while 
there is generally a detachment and critical distance between Salmond and her subject, the emphasis on Cook's 'enlightened' methodologies does seem overstated in places. Although Cook's attempts to control sexual liaisons between his crew and locals, and minimise shootings and reprisals for theft of European property (not always particularly successfully) seem particularly praiseworthy, especially in comparison to his contemporaries, such 'enlightened' goals do seem at odds with some of his methods. Conflict and displays of arms were still a common part of his strategy: 'Three things made them our fast friends, Their own good Natured and benevolent disposition, gentle treatment on our part, and the dread of our fire Arms' (Cook, cited in Salmond, 2004, p. 276). Salmond clearly records that locals were shot regularly with small-shot, sometimes with lethal results, as part of tactics of intimidation as much as punitive acts. If the level of confrontation on the third voyage escalated, this does not preclude earlier confrontations between the Europeans and locals, and between Cook and his crew.

On the whole, though, any work of this size on this subject would have its limitations, and it should be said that Salmond's book succeeds in retelling Cook's journeys in a fresh and stimulating manner. Her book is deservedly popular, proving both entertaining and laudable in its critical balance.

\section{Notes}

${ }^{1}$ Criticisms of Cook's reputation include Hauanani-Kay Trask's linking of Cook to the colonial violence and disease, and the position signified by the title of Paddy Wainburranga's anti-colonial painting, Too Many Captain Cooks (Thomas, 2004, p. xxxii).

${ }^{2}$ For example, the cultural comparisons made by Cook and others, between different islanders' qualities and their relative merits and levels of civilisation, is described but not really analysed (in comparison, see Guest, 2003).

\section{References}

Beaglehole, J. C. (Ed.) (1955-69). The journals of Captain James Cook (three volumes). Cambridge: Cambridge University Press; Hakluyt Society.

Calder, A., Lamb, J., \& Orr, B. (Eds.) (1999). Voyages and beaches. Honolulu: University of Hawaii Press.

Guest, H. (2003). Cook in Tonga: terms of trade. In R. Edmond \& V. Smith (Eds.), Islands in history and representation (pp. 95-115). London: Routledge.

Salmond, A. (2004). The trial of the cannibal dog: Captain Cook in the South Seas. Auckland: Penguin.

Thomas, N. (2004). Discoveries: The Voyages of Captain Cook. London: Penguin. 